\title{
La crítica de Siegfried Kracauer a la propaganda comunista'
}

\section{Q Gábor Gángó}

Universidad Católica Pázmány Péter; Instituto de Filosofía, Centro de Investigación de las Ciencias del Espíritu de la Academia de Ciencias, Hungría

Fecha de recepción: 7/7/2019. Fecha de aceptación: 31/7/2019.

\section{Resumen}

El presente artículo se propone analizar las interpretaciones de Siegfried Kracauer sobre la propaganda comunista en los estados satélite de Europa Oriental durante la Guerra Fría. Para ello se recurre a informes y borradores inéditos y a su trabajo de investigación que lleva por título Satellitenmentalität (Mentalidad satélite). Se compara aquí la metodología utilizada en estas investigaciones de Kracauer como exiliado en los Estados Unidos con los estudios y metodología de Los empleados (Die Angestellten) y otros trabajos de la Alemania de Weimar. Se destaca y se intenta demostrar hasta qué punto el interés de Kracauer en la manipulación ideológica y la propaganda comunistas se debió a la fragilidad laboral de su condición de emigrado.

Palabras clave: Guerra Fría; teoría de la manipulación; teoría del cine; comunismo; propaganda.

\section{Siegfried Kracauer's Critique of Communist Propaganda}

\begin{abstract}
This article aims at analysing Siegfried Kracauer's interpretations of communist propaganda in satellite states during the Cold War. The unfinished investigation conducted in Satellitenmentalität (Satellite mentality) and unpublished sketches and reports are here studied for such purpose. The research methodology carried out by Kracauer in the United States is here compared with that used in The
\end{abstract}


Salaried Masses (Die Angestellten) and other studies from the Weimar Republic. It is an objetive of this paper to show to what extent Kracauer's interest in communist ideological manipulation and propaganda is due to his unstable working conditions as an émigré.

Keywords: Cold War; Theory of Manipulation; Theory of the Film; Communism; Propaganda.

\section{Introducción}

En sus estudios y críticas de cine sobre la propaganda nacionalsocialista, Siegfried Kracauer se esforzó por desarrollar una teoría de la estética de la manipulación. Llegó a la conclusión de que el propósito de la propaganda nacionalsocialista consistía más en su "fidelidad a la realidad" que en la falsificación de la realidad por medio de la creación de una ilusión totalitaria. Por lo tanto, él descubrió el factor esencial de su funcionamiento, esto es, el montaje tendenciosamente asincrónico de secciones en imagen, sonido y música; secciones que por lo demás estén en condiciones de reflejar fielmente la realidad.

El objetivo de mi artículo es mostrar que y cómo Kracauer durante la Guerra Fría intentó adaptar sus perspectivas sobre la propaganda comunista en los estados satélite de Europa Oriental, o bien en qué medida sus posiciones se modificaron en relación con las expectativas de sus empleadores norteamericanos.

Sobre la base de sus escritos pertinentes que van desde Satellitenmentalität [Mentalidad satélite] hasta algunos informes y borradores de la obra póstuma inéditos y hasta ahora desatendidos sobre la comunicación oficial, u opositora, en los países comunistas se aclaran los esfuerzos de Kracauer para resguardar el conjunto de su obra con núcleos temáticos en la metodología sociológica y la tematización crítica de los medios también en los escritos ocasionales redactados en los Estados Unidos.

Mi estudio es una contribución para responder la pregunta de si y en qué medida Kracauer estaba en condiciones, sobre la base de informaciones accesibles para él sobre el cerrado mundo de la vida de los países comunistas, de desarrollar una fenomenología de la vida cotidiana de Europa Oriental en los años cincuenta que, de acuerdo con sus intenciones, fuera comparable con los análisis de Los empleados y otros de sus bestsellers de la Alemania de Weimar.

Los análisis de la propaganda comunista deben ser insertados en el contexto del trabajo de experto de Kracauer en los Estados Unidos. Sus escritos de los años cincuenta solamente destacaban los aspectos débiles de su trabajo, que provenían de su posición precaria en los Estados Unidos y de su dependencia intelectual respecto de quienes lo contrataban.

Como es sabido, Kracauer recibió una doble crítica a su investigación sobre los medios referentes a la propaganda nazi. La crítica formulada por Adorno ha sido ampliamente interpretada en la bibliografía pertinente. Para nuestros planteos 
son de mayor importancia aquellas observaciones con las cuales Martin Schapiro acompañó los primeros intentos de Kracauer. Schapiro tomó ante todo el trabajo de Kracauer como un enfoque científico. Él comprendió quizás que Kracauer estaba interesado ante todo en el método. Pero no quería financiar con dinero norteamericano un trabajo de conocimiento teórico, sino uno relacionado con la aplicación. Más allá de esto, Schapiro reconocía claramente el hecho de que la manipulación era un rasgo de carácter "to the whole field of the film”; ${ }^{2}$ esto es, la visión de Kracauer sería válida también en el ámbito de los filmes norteamericanos.

De allí que la manipulación no sea una anomalía, sino un elemento inherente al film. De esto se sigue que un análisis fenomenológico de la estética total de los filmes no está en condiciones de poner al descubierto la esencia de los regímenes totalitarios. Con la revelación del carácter esencial manipulatorio del film se saca a la luz solamente uno de los rasgos de carácter que podrían aplicárseles a los filmes en cualquier sistema político. Schapiro vio acertadamente que el elogio kracaueriano de la "transmisión de información" democrática es insostenible. Por eso no apoyó las investigaciones teóricas.

El libro Satellitenmentalität, sobre el comportamiento de los europeos orientales frente a la propaganda comunista, fue la segunda recuperación por parte de Kracauer de la metodología de su famoso opúsculo sobre el proletariado "white-collar"3 de la gran ciudad alemana. La primera recuperación fue el libro sobre Offenbach, en relación con el cual Kracauer le escribió a Emil Lederer las siguientes palabras: "Como ve, permanezco fiel a la sociología y también al método desarrollado en Los

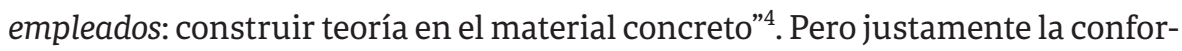
mación teórica no interesaba a sus contratantes norteamericanos.

\section{El origen de Satellitenmentalität}

Como lo indican los materiales que Kracauer había redactado para la UNESCO a favor de la lucha contra la propagación del "virus" de la propaganda comunista entre las clases bajas, Satellitenmentalität no fue un trabajo científico, sino material de consulta en la lucha contra la propaganda de la Rusia soviética. ${ }^{5}$

\footnotetext{
2"Para todo el ámbito del cine". (Nota de la trad.).

3 "De cuello blanco". (Nota de la trad.).

4 Carta de Kracauer a Emil Lederer, París, 28 de febrero de 1936.

5 "In a speech on national defence delivered soon after his return from the Paris Conference, Assistant Secretary of State William Benton remarked that 'we are committed generally to a concern with the wellbeing of peoples everywhere, not for reasons of altruism but in our own interest and for our own protection.' His remark leaves no doubt about the purposefulness of those proposals which tend to initiate distressed and backward populations into the elementary blessings of civilisation. This altruism pays indeed, for in thus joining forces with the relief agencies proper, UNESCO helps immunize the underprivileged to the virus of Communist propaganda, their professional affliction" (Kracauer, s.f.: 10). En relación con la formación de Satellitenmentalität ver "Nachbemerkung und editorische Notiz" [Comentario posterior y nota editorial], en: Kracauer, 2012a: 827876, aquí: 859ss.
} 
Los materiales fueron reunidos por la United States Information Agency [Agencia de Información de los Estados Unidos], representada por el Dr. Leo Löwenthal, y cedidos a Kracauer para la investigación y publicación, bajo reserva de una autorización del manuscrito. ${ }^{6}$

El trabajo de edición de las entrevistas fue de Paul L. Berkman. ${ }^{7}$ El libro fue escrito por Kracauer con el plazo límite del 31 de enero de 1954 por 1000 dólares en pagos semanales de 75 dólares. ${ }^{8}$ Fue Kracauer quien escribió el libro, pero las entrevistas no habían sido realizadas por él. ${ }^{9} \mathrm{El}$ volumen aparecería mucho más tarde, a mediados de agosto de 1956, es decir, antes de la revolución de $1956{ }^{10}$

Satellitenmentalität es semejante a Los empleados también en el aspecto en que los sujetos entrevistados pertenecían más bien a la clase de los empleados. Este paralelo continuó siendo desarrollado en otro pasaje de Kracauer, por medio de la afirmación de que los europeos del este no eran sensibles a la ideología proletaria, sino a la cultura de masas occidental. ${ }^{11}$

El proyecto sobre la mentalidad de Europa Oriental fue intercalado dentro del gran plan de Kracauer sobre la historia y teoría del film sin ser incluido allí dentro. Kracauer separó cautelosamente los dos proyectos uno del otro. Como le escribió a Bernhard Guttmann el 29 de agosto de 1954: "Pero por suerte me resultará más liviano y en todo caso más agradable el próximo año y medio o dos años, pues se me ha dado nuevamente la posibilidad de volver a mi libro sobre la estética del film, que se encuentra a medio hacer y abandonado desde hace dos años."

\section{Estética y propaganda en Satellitenmentalität}

En su Caligari, Kracauer formuló la tesis de que el acceso a la realidad es la primera condición de la libertad. Su volumen de entrevistas escritas con Paul L. Berkman del año 1956, Satellitenmentalität, se esfuerza en mostrar un esfuerzo inverso, el de la propaganda comunista en los países de Europa Oriental. En

6 Carta de Charles Y. Glock a Kracauer, Nueva York, 26 de octubre de 1953.

7 Carta de Kracauer a Charles Y. Glock, The Wildmere, Lago Minnewaska, Condado de Ulster, Nueva York, 5 de agosto de 1953.

8 Carta de Kracauer a Charles Y. Glock (Bureau of Applied Social Research, Universidad de Columbia), Nueva York, 27 de octubre de 1953

9 "En el último tiempo dirigí allí, y escribí su mayor parte, un estudio sobre la mentalidad satélite que se basaba en entrevistas y que fue reelaborado por mí en un pequeño libro". Carta de Kracauer a Bernhard Guttmann, Nueva York, 29 de agosto de 1954

10 Carta de David L. Sills (también un miembro del Bureau) a Kracauer, Nueva York, 17 de agosto de 1956: "congratulate you on the publication of Satellite Mentality".

11 "In his article, 'Europe's Battered Muse' (The Saturday Review of Literature, April 19, 1947), Leo Lania has some pleasant things to tell about our popularity in countries exposed to the impact of Russian culture. 'The Polish people are eager and anxious to hear our voice, to read our books, to see our plays.' Ant the Czechs? Leftminded, as they may be, 'they prefer, so it seems, Steinbeck and Hemingway, the 'Gone-with-the-wind' Mitchell and Bromfield to any book the Soviet Union has to offer.' Corroborating Mr. Lania's impressions, other observers report that the Prague moviegoers are so overfed with the display of Russian films that they crowd the few theaters still exhibiting Hollywood pictures." (Kracauer, s.f.: 17-18). 
oposición a sus aproximaciones más tempranas centradas en el film, en este libro, con la palabra 'propaganda' Kracauer no comprendió otra cosa que adoctrinamiento político. "La propaganda, dice él [es decir, un abogado polaco] es omnipresente (en la prensa, en asambleas, por los altoparlantes, carteles, exposiciones, etc.) y lo persigue a uno todo el tiempo, uno no tiene un momento de tranquilidad ni puede escaparse de su influencia". ${ }^{12}$ El trabajo Satellitenmentalität pone en un primer plano solamente los elementos verbales de la propaganda; elementos que construyen un mundo posible de manera más coherente y claramente más falsificable. De esta manera, Kracauer transformaba la propaganda comunista en retórica y renunciaba al análisis de los aspectos estéticos en lo referente a su mecanismo de influencia. Satellitenmentalität aplicaba así no solamente el método de entrevista sociológico de Los empleados, sino también las perspectivas del análisis de propaganda kracaueriano de 1938-1942 al servicio de investigación de propaganda norteamericano durante la Guerra Fría.

El mismo jurista polaco dice: "Con el tiempo la gente, sin quererlo, comienza a adoptar cosas determinadas, por ejemplo la forma de argumentación". ${ }^{13} \mathrm{En}$ consecuencia la gente en Europa Oriental escucha argumentos, es decir, ellos expresan su consentimiento frente a todo lo que sucede con ellos: la propaganda comunista totalitaria (y esta perspectiva se encuentra presente en el libro de Kracauer y Berkman mucho más de forma latente) no es totalitaria en el mismo sentido de la Alemania nacionalsocialista. Los ciudadanos de los estados satélite viven en una pobreza de colores, imágenes y formas, únicamente con un mundo poblado de frases sonoras y escritas. La Alemania nacionalsocialista era, en contraposición, un mundo compuesto estéticamente, cuya belleza ni siquiera en cierto sentido fue objetada por Kracauer. Como afirmaba Kracauer basándose en el proceso de composición de los filmes de Leni Riefenstahl, o de declaraciones de la directora, en este mundo la vida estaba entretejida inseparablemente de su reflejo propagandístico. Allí, la esencia de la propaganda no era tanto la retórica como más bien lo era la propensión de la condition humaine hacia la totalidad. En esta atmósfera quedaba fuera, según la vigencia de Kracauer, toda pretensión de verdad.

A partir de los análisis de Satellitenmentalität se aclara en cambio que, en Europa del Este, la propaganda totalitaria estaba muy lejos de ser realmente universal, pues solamente una parte de los consultados dieron aprobación a algunas de las tesis de la propaganda (como él escribió en el título del octavo capítulo "Propaganda totalitaria: fortalezas y debilidades"). Se puede en efecto alcanzar la verdad por medio de operaciones lógicas sobre las frases de propaganda. Como un "yoga enthusiast" ${ }^{\text {"14 }}$ dijo: "Ludas Matyi escribió la verdad. ${ }^{15}$ Ellos pusieron en ridículo a Occidente, pero todo lo que entretanto publicaron, podría ser entendido como

12Carta de Kracauer a Bernhard Guttmann, Nueva York, 29 de agosto de 1954.

13Carta de Kracauer a Berkman 1956: 90-91; Kracauer/Berkman, 2012: 294.

14 Entusiasta del yoga. En inglés en el original. (Nota de la trad.).

15 Ludas Matyi fue una publicación satírica húngara. (Nota. de la trad.). 
si pasara en nuestro país". ${ }^{16}$ Un entrevistado húngaro dio un ejemplo de esto que puede leerse entre líneas: "Magyar Nemzet ${ }^{17}$ informó detalladamente sobre los discursos de los delegados soviéticos y de otros comunistas en las Naciones Unidas... a partir de los cuales pude enterarme algo del punto de vista del mundo libre"18. En virtud de la lógica, la ilustración en los estados satélite puede comenzar dentro del mundo de la propaganda: "El comportamiento contrario al total rechazo es la inversión; se basa en la convicción de que uno debe, para llegar a la verdad, aceptar solamente lo contrario de todo lo que decían los comunistas"19. Un salto entre el discurso manipulador y el racional no es pues necesario.

Kracauer ajustó cuentas con sus perspectivas sobre la estética de la manipulación en su Caligari. Subordinó allí la manipulación a las cuestiones técnicas del montaje:

El arte del montaje fue desarrollado en Alemania mucho tiempo antes de 1933. [...] Gracias a esta tradición, los nazis sabían cómo los tres medios fílmicos [film media] - comentario, imagen, sonido - han de ser aplicados. Con una marcada sensibilidad para el montaje explotaron todos los medios, tanto, que el efecto final frecuentemente resultaba la mezcla de significados diferentes en medios diferentes. (Kracauer, 2012b: 335-336).

Entre los motivos de este ajuste de cuentas, debería también seguramente señalarse el hecho de que Kracauer, en sus críticas cinematográficas posteriores a la Segunda Guerra Mundial, debió constatar que el film norteamericano se movía como antes en el contexto de la propaganda antinazi y en consecuencia no renunció a las maniobras de la propaganda, ni en tiempos de guerra ni de paz.

El carácter absolutamente limitado de la racionalidad que posee el film fue reconocido sin duda en el capítulo "Film y propaganda" de su Teoría del cine de 1965. Kracauer realizó una inversión en la relación de prioridad entre irracionalidad y propaganda cinematográfica. No se pone tanto énfasis en examinar con qué elementos el arte cinematográfico nacionalsocialista contribuyó para la destrucción de la razón [Vernunft], sino en mostrar cómo la potencia irracional universalmente vigente inherente del film entre otras cosas, se manifestaba también en la propaganda nacionalsocialista. En relación con las emociones de la música que modifican el significado en la Teoría del cine de Kracauer, se plantearon soluciones en paralelo en el triunfo del film propagandístico nazi en Occidente con aquellas soluciones presentes en películas de la naturaleza de Walt Disney.

En tanto Kracauer se proponía elaborar una estética de la propaganda, dio los primeros pasos en dirección a la estética de la manipulación. Estos primeros

16 Carta de Kracauer a Berkman 1956: 113; Kracauer/Berkman, 2012: 318.

17 Magyar Nemzet es un periódico húngaro. (Nota de la trad.).

18 Carta de Kracauer a Berkman 1956: 116. Kracauer/Berkman 2012; aquí: 322.

19 Carta de Kracauer a Berkman 1956: 111. Kracauer/Berkman 2012: 316. 
pasos no fueron seguidos en adelante. Probablemente porque se había hecho evidente que la manipulación es una categoría estética más amplia y originaria, de la cual la propaganda política o de guerra constituye solo un caso. Por eso, en Satellitenmentalität no aparecen en primer plano de los análisis los aspectos manipuladores de la propaganda, sino los retórico-adoctrinadores.

También la escasez de información independiente sobre los estados de Europa Oriental contribuyó a que Satellitenmentalität no pudiera alcanzar su objetivo. En el caso de Los empleados, Kracauer se pudo apoyar en un saber independiente sobre el mundo, a partir del cual reflejó la imagen del mundo y la falsa conciencia de los empleados. No fue posible en cambio sostener las entrevistas realizadas a los refugiados tanto para una descripción "objetiva”, como también para un reflejo "subjetivo-falsificado" de la vida en los países comunistas. ${ }^{20}$

\section{Kracauer y la revolución de 1956 en Hungría}

Después de la represión del levantamiento anticomunista en Hungría a finales de 1956, Alexander Dallin comenzó un proyecto de investigación sobre un tema en el que él quería incluir a Kracauer. La respuesta de Kracauer fue cortés y afirmativa: "Really, I am very interested in your project". ${ }^{21}$ También en este caso, actuó Kracauer como experto en entrevistas colectivas con emigrantes. ${ }^{22}$ La conversación tuvo lugar el 13 de abril de 1957 en el marco de un almuerzo, ${ }^{23}$ en el cual Kracauer había hecho sus propuestas para la investigación futura. ${ }^{24}$

Lo que Kracauer en esta conversación debió haber defendido es conocido a partir de sus apuntes para esta conversación. Sobre la propaganda escribió en los puntos 9 y 10 de su esbozo:

9.: How do they [i.e. refugees from Hungary] visualize democracy? Do they at all? Or has Communist prop. inadvertently shaped their minds?

10.: Find out about influence of Communist prop. on those who abhor Communism. $^{25}$

Estos pasajes muestran que Kracauer se alejó fundamentalmente en este examen de la posición fundamental de Satellitenmentalität. Lo que él buscaba, no eran

20 Kracauer mismo señaló que las entrevistas no eran fuentes confiables: "e.g., "Refugees from E. Germany report that..." is not reliable" (Kracauer, 1952: $N^{\circ} 1$, p. 2)

21 "Realmente, estoy muy interesado en su proyecto" [en inglés en el original]. Carta de Kracauer al Dr. Alexander Dallin, Nueva York, 19 de mayo de 1957.

22 Carta de Alexander Dallin a Kracauer, Nueva York, 22 de abril de 1957.

23 Carta de Florence C. Dallin a Kracauer, Nueva York, 5 de abril de 1957.

24 Carta de Alexander Dallin a Kracauer, Nueva York, 22 de abril de 1957.

25 9.: ¿¿Cómo ellos [esto es, refugiados de Hungría] visualizan la democracia? ¿Lo hacen en algún grado? ¿O la propaganda comunista ha involuntariamente modelado sus mentes?" 10.: "Averiguar sobre la influencia de la propaganda comunista en aquellos que aborrecen el comunismo." (Nota de la trad.). 
las estrategias de oposición o disidencia posibles dentro del sistema, sino los rastros posibles de la infección comunista en los refugiados. A diferencia de los disidentes esporádicos durante los tempranos años cincuenta, la huida masiva post-1956 despertó desconfianza y activó los reflejos defensivos.

\section{Conclusión}

En su emigración, Kracauer se esforzó todo el tiempo en concluir de la manera lo más completa posible su obra sobre fenomenología de la cultura. Los escritos de ocasión y análisis aplicados sobre Europa del Este durante la Guerra Fría pertenecen también al contexto de sus obras tardías, que están vinculadas por muchos hilos tanto temática como metodológicamente a las obras de teoría del film o de la historia. Para un abordaje exhaustivo de la obra kracaueriana desde la perspectiva de la historia de las ideas, también estos accesorios deben ser observados, los que pueden sacar a la luz no solamente los límites inevitables de la autonomía intelectual del Kracauer tardío, sino también algunos presupuestos latentes en las obras de teoría de la cultura.

Kracauer no tenía especial interés en Europa Oriental. No se sintió demasiado impresionado por la publicación polaca de su Caligari ${ }^{26}$ y sus palabras irónicocorteses (él estaba "really" "very interested"27 en la situación post 1956 en Hungría) muestran que su interés estaba únicamente vinculado con las posibilidades laborales. De ahí que sus esfuerzos por conseguir una unidad temática externa para su obra no fueron acompañados por un interés intelectual unitario en lo interno.

26 "It might interest you that my From Caligari To Hitler, though out of print, is still on the move. Recently I received the unabridged Polish edition; strange for an Iron Curtain country, they have even paid for it." Carta de Kracauer al Prof. Everett C. Hughes, Departamento de Sociología, Universidad de Chicago, Nueva York, $1^{\circ}$ de marzo de 1959.

27 "Realmente"; "muy interesado" (Nota de la trad.). 


\section{Q Bibliografía}

"Kracauer, S. (2012a). Studien zu Massenmedien und Propaganda. Edición de Christian Fleck y Berndt Stiegler, con la colaboración de Joachim Heck y Maren Neumann. En Kracauer, S., Siegfried Kracauer Werke. Ed. de Inka Mülder-Bach e Ingrid Belke. Tomo 2.2. Frankfurt a/M: Suhrkamp, pp. 827-876.

" Kracauer, S. (2012b). Von Caligari zu Hitler. Eine psychologische Geschichte des deutschen Films. Edición de Sabine Biebl, con la colaboración de Gerhard Hommer. En Kracauer, S., Siegrfried Kracauer Werke. Ed. de Inka Mülder-Bach e Ingrid Belke. Vol. 2.1. Frankfurt a/M: Suhrkamp, pp. 335-336.

" Kracauer, S. (1952). Instructional Manual (including code definitions and symbols) for Qualitative Content Analysis. Experimental Draft $N^{\circ} 1$ y 2. Kracauer Nachlass, Deutsches Literaturarchiv.

" Kracauer, S. (s.f.). Peace, Culture and Power Politics. Remarks on UNESCO. Manuscrito mecanografiado, $30 \mathrm{pp}$.

" Kracauer, S. y P. L. Berkman (2012). "Satellitenmentalität". En Kracauer, S. Siegfried Kracauer Werke. Ed. de Inka Mülder-Bach e Ingrid Belke. Tomo 2.2. Frankfurt a/M: Suhrkamp, pp. 191-405. 